\title{
POWER UP: A Persuasive Writing Strategy for Secondary Students with Emotional and Behavioral Disorders
}

\author{
Philip D. Nordness ${ }^{1}$, Jessica L. Hagaman ${ }^{1}$, Rebecca Herskovitz ${ }^{2}$ \& Elizabeth Leader-Janssen ${ }^{1}$ \\ ${ }^{1}$ Department of Special Education and Communication Disorders, University of Nebraska at Omaha, Omaha, NE, \\ USA \\ ${ }^{2}$ Amherst Regional High School, Amherst, MA, USA \\ Correspondence: Philip D. Nordness, Department of Special Education and Communication Disorders, \\ Univesrity of Nebraska at Omaha, Omaha, NE 68118, USA. E-mail: pnordness@unomaha.edu
}

Received: April 19, 2019 Accepted: May18, $2019 \quad$ Online Published: June 13, 2019

doi:10.5539/jel.v8n4p32 URL: https://doi.org/10.5539/jel.v8n4p32

\begin{abstract}
In the area of written expression, students with emotional and behavioral disorders (EBD) typically perform one to two grades below their same age, non-disabled peers. Unfortunately, there is a lack of research on writing interventions to improve these outcomes. The purpose of this study was to examine the effect of a persuasive writing strategy called POWER UP to improve the quality of persuasive essays for secondary students with EBD. The results suggest that a mnemonic strategy based on the Self-Regulated Strategy Development Model (SRSD) can improve the quality of persuasive writing essays for secondary students with EBD.
\end{abstract}

Keywords: emotional disturbance, persuasive writing, special education, SRSD, behavior disorders, strategies

\section{Introduction}

Research on the academic status of students with emotional and behavioral disorders (EBD) has consistently demonstrated that they are one to two grade levels below their same age peers in reading, written expression, and mathematics (Trout, Nordness, Pierce, \& Epstein, 2003). In addition, when compared to other disability groups, students with EBD have higher rates of school failure and are more likely to drop out of school (Reid, Gonzalas, Nordness, Trout, \& Epstein, 2004). Despite the poor academic achievement of students with EBD, there is a paucity of research on academic interventions to improve these outcomes. In a review of academic intervention research from 1975-2002, Mooney, Epstein, Reid and Nelson (2003) found that over a 27-year period only 87 studies were conducted on academic interventions for students with EBD. Reading and mathematics accounted for $59(68 \%)$ of those studies, whereas written expression accounted for only $10(11 \%)$. In addition, from 19962002, there were no writing intervention studies published specifically for students with EBD. Furthermore, Lane (2004) noted that academic interventions targeting written expression represent the least developed instructional area for students with EBD.

In analyzing data from a standardized measure, Nelson, Benner, Lane and Smith (2004) found that students with EBD scored well below average in the area of written language. In addition, Benner, Mattison, Nelson, and Ralston (2009) found that when comparing subtest scores in the area of mathematics, reading, and written language, students with EBD obtained the lowest mean score in the area of written language. These findings are significant when we consider that writing is critical to student success in the classroom, for passing state-wide tests, and for living a successful life independently after high school. While reading is the foundation to learning and mathematics plays a key role in daily living, writing is the primary means by which students convey knowledge (Graham, 2005). For students with EBD, this can be particularly difficult because good writing involves receptive and expressive language processes that require students to plan, organize, and evaluate (Reid, Trout, \& Schwartz, 2005; Taft \& Mason, 2011). These metacognitive demands are often difficult for students with EBD because they lack the strategies necessary to become efficient learners (Mooney et al., 2003).

While from 1996-2002 there were no published studies on writing interventions for students with EBD, in the last ten years there have been a number of studies conducted using the Self-Regulated Strategy Development Model (SRSD; Lane, Harris, Graham, Weisenbach, Brindle, \& Morphy, 2008; Little, Lane, Harris, Graham, Story, \& Sandmel, 2010; Mason, Kubina, Valasa, \& Cramer, 2010; Mason \& Shriner, 2008; Mason, Kubina, \& 
Hoover, 2013), which is an instructional approach used for improving writing skills for students with disabilities. SRSD includes six instructional stages designed to promote writing independence by teaching students cognitive and self-regulation strategies (Mason et al., 2010). These studies provide some encouraging evidence for the use of SRSD for improving written expression for elementary and middle schools students with EBD, however, only one of these (Mason et al., 2013) have examined the use of writing strategies for high school students with EBD. Mason et al. (2013) investigated the use of the POW + TREE strategy for persuasive quick writes with 3 students with EBD. The results from this study demonstrated small to medium effects for improvement in persuasive writing with some degree of variability across measures (e.g., word count). In spite of these encouraging results, there remains a need for additional research that examines the utility of an SRSD approach to improve persuasive writing as measured by state and district standards. Moreover, the strategy needs to be consistent with state guidelines for writing tests, which often requires the test to be completed on the computer, with scrap paper permitted for pre-writing.

\subsection{POWER UP Strategy}

One type of strategy to help students with disabilities improve their writing skills is the mnemonic strategy POWER. POWER was developed by Englert and colleagues in 1988 and stands for Plan, Organize, Write, Edit, and Revise (Englert, Raphael, Anderson, Anthony, Fear, \& Gregg, 1988). POWER has been researched extensively for students with learning disabilities (Englert et al., 1988; Englert Raphael, Anderson, Anthony, \& Stevens, 1991). However, despite the positive effects of POWER with these populations, it has not been examined for secondary students with EBD.

To extend the research on POWER, we developed the POWER UP strategy to be used for secondary students with EBD. We followed the same principles for POWER, but we made a few adjustments to meet the needs of our participants. First, we changed the E to signify "end" and added the mnemonic UP to prompt students "Update" and "Publish". We included these additional steps because upon classroom observations, it became evident that students needed additional cueing to include a conclusion section (End). Furthermore, using both Revise and Update as separate steps helps students to understand that Revise actually means re-read the whole essay and identify any necessary changes and revisions, then Update means to make those changes as necessary during the re-reading process. Adding the Publish step cued the students to save and print as necessary. Including the word Publish encouraged students to understand that their writing is destined for a particular audience and that audience ought to be considered when developing the arguments.

In addition to the mnemonic prompts, a major component of the POWER UP intervention was the development of a graphic organizer to help the students organize their essay. It has been demonstrated that most students with disabilities struggle during the planning stage of writing (Graham, Harris, MacArthur, \& Schwartz, 1991), however, it is one of the most important steps of effective writing. As a result, students with disabilities often need an additional support for organizing their essay. The graphic organizer was developed to be used in the "Plan" step of the strategy. The graphic organizer is in the shape of a diamond that is created by folding a piece of white paper in half, and then folding it in half again so that the paper resembles four squares (see Figure 1). When students hold the paper as a diamond shape, the top diamond is where the students write their opinion, and the diamonds below are where the students write the supporting arguments. Since students are only allowed a single white sheet of paper during the statewide writing assessment, the diamond graphic organizer assists the students in planning the content that will be addressed in their essay.

We chose to implement the POWER UP strategy because the sequence of steps mirrors the writing process as outlined by the state's curriculum standards. For instance, the language arts writing standards include specific objectives for using pre-writing tools, organizing thoughts through thesis statements, structured arguments, and parallel structure. After this, the standards measure the steps of revising, editing, and publishing the document. In addition, the standards emphasize the importance of understanding a particular genre - such as persuasive essays - and the appropriate organization, structure, and engagement with the audience needed therein.

The current study seeks to extend previous studies on POWER, SRSD and persuasive writing instruction for secondary students with EBD. First, as mentioned earlier, a few steps in the POWER strategy were modified to meet the needs of our participants. These revisions included changing the "Evaluation" step to "End", and adding an "Update" and "Publish" step. In addition, during the 'Plan' step of the POWER UP strategy, students were taught to use a specific graphic organizer to plan and organize their thoughts prior to writing. Second, previous studies investigating the use of SRSD writing strategies for students with EBD in high school settings is limited. The following study seeks to extend the line of research on SRSD by examining the effectiveness of the POWER UP strategy as measured by the statewide assessment for student writing performance. Finally, previous 
studies investigating the effects of SRSD on writing for students with EBD have used researchers or trained doctoral students to deliver instruction. In this study the intervention was conducted by a teacher in a self-contained school for students with EBD who learned SRSD during her graduate program in special education.

\section{Method}

\subsection{Participants}

The participants in this study were three African American high school students ages 18 and 19, who were receiving special education services for EBD in a self-contained setting in a large metropolitan community. Each of the participants were selected to participate in this study because they had an IEP goal for writing and because they would be participating in the statewide writing assessment.

Christian was 19 years old and receiving special education services for EBD because he had experienced significant struggles with mental illness, drug addiction, and delinquency. He was living in a group home for young adults with mental illness during the study. In the classroom, he typically displayed average knowledge of writing conventions (e.g., spelling, grammar, punctuation) and strong voice, but difficulty with organization and using logical idea flow for content as measured by curriculum-based assignments. He generally wrote for the entire time allotted, but his writing was not always coherent. Christian had an average IQ score of 87 as measured by the Wechsler Intelligence Scale for Children-Fourth Edition (WISC-IV; Wechsler, 2003).

KaVionne was 18 and had been diagnosed with conduct disorder and had spent time in a youth detention center. In the classroom, his writing typically displayed little to no sentence structure, poor spelling, no punctuation, no organization, and minimal development of ideas as measured by curriculum-based assignments. He generally wrote as little as possible. KaVionne had an IQ score of 81, which would put him in the low average range.

Tyler was 18 and struggled with truancy, impulsiveness, and was homeless at the time of this study, staying with different friends at different times. In the classroom, his writing typically displayed average knowledge of conventions, logical development of ideas, but minimal organization, voice, or details as measured by curriculum-based assignments. He generally wrote as little as possible. Tyler had an average IQ of 92 .

\subsection{Setting}

The study was conducted in the spring semester at an urban, self-contained public school for students with EBD in the Midwest. The school includes an elementary wing with approximately 17 students in grades first through sixth, and a secondary wing with approximately 88 students from seventh through twelfth grade. In the secondary wing, approximately $59 \%$ of the students were from minority backgrounds, $80 \%$ were receiving free and reduced lunch, and all of the students were receiving special education services for EBD. All instruction during the study took place in the afternoon during the students' regularly scheduled fifth period. This half hour block included a functional writing curriculum focusing on elements of persuasive writing that would be measured on the statewide assessment.

\subsection{Dependent Variable}

The dependent variable for this study was the 2012-2013 Nebraska State Accountability (NeSA) rubric for Persuasive Writing, an analytic 4-trait state rubric for persuasive writing (Nebraska Department of Education, 2012). Persuasive Essays receive a score of $0-4$ on each of the four categories: (1) Idea Content; (2) Organization; (3) Voice/Word Choice; and (4) Sentence Fluency. Each score of 0-4 was multiplied by the appropriate percentage/weight: (1) Ideas Content (0-4) x 35; (2) Organization (0-4) x 25; (3) Voice/Word Choice $(0-4)$ x 20; and (4) Sentence Fluency (0-4) x 20. Based on these numbers, the lowest possible score a student can earn is 0 and the highest is 400 . Raters were given anchor papers representing each score level. The use of holistic scoring with anchor papers has been developed and used in previous research (see Mason, Kubina, Valasa, \& Cramer, 2010; Harris, Graham, \& Mason, 2006; Mason \& Shriner, 2008).

To score the papers reliably and with fidelity, the teacher and a graduate student used the Nebraska State Accountability (NeSA) Writing Rubric/Training for Grade 11. This training included a PowerPoint presentation on the procedures for scoring the papers and a 52-page scoring guide that included examples of how to score each of the four categories. To establish inter-rater agreement papers were coded so that raters were blind to the student and the testing phase (e.g., baseline versus post instruction). During scoring training, scorers rated written persuasive responses until they achieved 95\% reliability over 10 responses. Inter-rater reliability for quality was $90 \%$ for exact agreement and $95 \%$ for within 1-point agreement. For disagreements, scores were averaged. 
Number of words written. The number of words written was determined using the word count function of Microsoft Word. To eliminate any potential error, scorers also independently verified this word count by reading each response and counting the words by hand.

\subsection{Independent Variable}

The SRSD model developed by Harris and Graham (1996) was used to teach the POWER UP strategy (see Table 1). There are six stages in the SRSD model. All six stages in the SRSD delivery model were incorporated into a minimum of four half hour lessons. Prior to instruction, the student and instructor collaboratively set a writing goal and students committed to learning the strategy. All lessons began with a review of previously learned material combined with memorization activities to facilitate memorization of the POWER UP strategy. In order to enhance motivation, students were instructed to graph their performance.

Table 1. SRSD stages and lesson in which the stage was addressed

\begin{tabular}{|c|c|c|}
\hline SRSD Stage & Description & Lesson \\
\hline Stage 1: Develop and & - Make sure students possesses the skills necessary to use the POWER UP strategy & - Lesson 1 \\
\hline Activate Background & - Task Analysis of the strategy & \\
\hline Knowledge & - Discuss what makes a good persuasive essay & \\
\hline Stage 2: Discuss the & - Discuss present writing performance & - Lesson 1 \\
\hline Strategy & $\begin{array}{l}\text { - Students analyze one of their own previously written essays and graph the number } \\
\text { of words/components } \\
\text { - Present the POWER UP strategy and all steps } \\
\text { - Model and discuss self-instructions } \\
\text { - Describe goal-setting and self-monitoring procedures }\end{array}$ & \\
\hline $\begin{array}{l}\text { Stage 3: Model the } \\
\text { Strategy }\end{array}$ & $\begin{array}{l}\text {-Teacher models POWER UP strategy ("Think-Aloud") using self-instructions, goal } \\
\text { setting, and self-monitoring }\end{array}$ & - Lesson 2 \\
\hline Stage 4: Memorize the & - Students commit to memory the strategy's steps & - Lessons $1,2,3, \& 4$ \\
\hline Strategy & $\begin{array}{l}\text {-Students do not necessarily need to achieve automaticity before moving to the next } \\
\text { step } \\
\text { - Provide students with a prompt or cue card }\end{array}$ & \\
\hline $\begin{array}{l}\text { Stage 5: Support the } \\
\text { Strategy }\end{array}$ & $\begin{array}{l}\text { - Collaborative Practice- Teacher models the strategy and works together with } \\
\text { students } \\
\text { - Scaffolding - Teacher provides more support initially, less support as students are } \\
\text { ready to use the strategy independently } \\
\text { - Students graph the number of essay parts } \\
\text { - Scaffolding continues until mastery (an essay with all components) }\end{array}$ & - Lessons 2, 3, \& 4 \\
\hline $\begin{array}{l}\text { Stage 6: Independent } \\
\text { Performance }\end{array}$ & $\begin{array}{l}\text { - Students perform the strategy without support or feedback and with goal-setting } \\
\text { and self-monitored procedures } \\
\text { - Reteaching the strategy may be in order } \\
\text { - Students are able to write an essay independently } \\
\text { - Teacher monitors to ensure proper strategy use and determine whether performance } \\
\text { improved }\end{array}$ & - Following lesson 4 \\
\hline
\end{tabular}

\subsection{Procedures}

Student performance was evaluated by examining persuasive responses written to a two to three sentence prompt during a 30-minute class period. The prompts were based on the state guidelines for persuasive writing and from curriculum-based measures (CBM) identified by the instructor. Students were asked to type their essays but were provided blank paper and pencils and pens for planning. After students typed their responses to the written prompt, each response was saved as a Word document. Any identifying information was removed and a code was assigned to the paper so scorers would be unaware of whose paper was being scored and the testing time (e.g., baseline versus post instruction). Typed essays were scored for quality as assessed by the state rubric and number of words (length).

A multiprobe multiple-baseline across participants design was used to assess participant performance before and after the POWER UP strategy instruction (Kazdin, 1982). During baseline instruction students were taught persuasive writing as they had been instructed in the past, which primarily consisted of brainstorming. Typical instruction consisted of providing students with a prompt (e.g., "There are many different jobs that people have in the world. Imagine that you have a chance to meet with the Governor to tell him to give an award to the people who do the most important job in the world. What do you think is the most important job that a person 
can have? Try to convince the Governor that you are correct. Be sure to explain your answer fully") and then asking them to brainstorm ideas and write them down on paper, and then provide a written response on the computer.

To obtain baseline data, participants were provided with a persuasive writing prompt, instructed to write as much as they could to explain their position, and convince the person who was going to read it. The class period met for a half hour every day. After about 10 minutes of direction and instruction, they had 20 minutes to type their response. Per state testing guidelines, paper and pencils were made available to the students and they were allowed to use any strategy that they typically used in writing. Participants could ask the instructor to read any word in the writing prompt they did not recognize. The instructor did not provide any additional support, assistance, or encouragement.

Baseline data were collected once a week on each student until a consistent pattern of performance was demonstrated. After three consistent baseline probes were identified, the first participant was randomly selected to learn the POWER UP strategy while the other students remained in baseline. The special education teacher delivered all instruction during the intervention phase. The teacher had been previously trained on SRSD and the POWER strategy during her graduate program in special education. In addition, she had conducted an action research project with the SRSD model and modified POWER UP strategy.

Written instruction took place daily after lunch during fifth period in the classroom, which at times included four to eight high school students with EBD. During the intervention instruction, the other students were receiving typical instruction, which included prompting the students to write, encouraging brainstorming strategies, and various approaches to outlining thoughts. It took participants four sessions over a one-week period to learn the POWER UP strategy.

\subsubsection{Instructional Procedures for Teaching the POWER UP Strategy}

Instruction was systematically scaffolded to gradually shift responsibility of strategy use from the instructor to the participant. Feedback and instructional support were individualized and faded as the participant began to master each step of the strategy. The SRSD model is criterion based, not time based. Therefore, students moved through the series of lessons and activities at their own pace until they were ready to use the strategy independently. Each participant received four 30-minute lessons individually until they were able to independently use each step of the strategy correctly.

Lesson 1: Developing background knowledge and introducing the strategy. The purpose of the first lesson was to develop students' background knowledge and introduce the POWER UP strategy. During the lesson the instructor discussed what "persuasion" and "writing" was and where we might use writing and persuasion in our daily lives. The students were then asked to think of times that they used written responses and/or persuasion. The instructor also introduced the steps in the POWER UP strategy through visuals (i.e., PowerPoint presentation, poster with steps). Each step in the strategy was reviewed and explained. The instructor then helped students to identify persuasive elements in one of their baseline essays. Together the students and the instructor determined whether an anchor essay included all parts of a persuasive essay. Then the students reviewed one of their essays written during baseline to determine what elements of persuasion were present and what steps the student used to write their essay (e.g., did they plan? Did they revise?). The instructor then provided examples of how to improve their written performance. The instructor concluded the lesson by verbally obtaining the student commitment to learning the strategy.

Lesson 2: Modeling and providing supported practice. In the second lesson (and all subsequent lessons), the instructor tested the student for memorization of the POWER UP strategy steps. The instructor then orally read a practice writing prompt and modeled how to use the POWER UP strategy to write a persuasive essay, including how to use the "idea diamond" graphic organizer (see Figure 1) to plan and organize ideas prior to writing. The instructor used self-statements and self-instructions throughout the modeling (e.g., "I remember that the first step in POWER UP is Plan, so I need to read the prompt and decide my opinion based on what the prompt is asking me. Okay. I can do this!"). After modeling, the instructor asked the student to identify the self-statements that were modeled and how they might have helped the writing process. In addition, the instructor asked the student to identify what each step of POWER UP looked like. Next, the instructor and the student collaboratively identified the components of a persuasive essay that were present in the instructor's essay. Lesson 2 ended by the instructor praising the student for hard work and reminding them that there would be a quiz on the strategy steps at the start of the next lesson. 


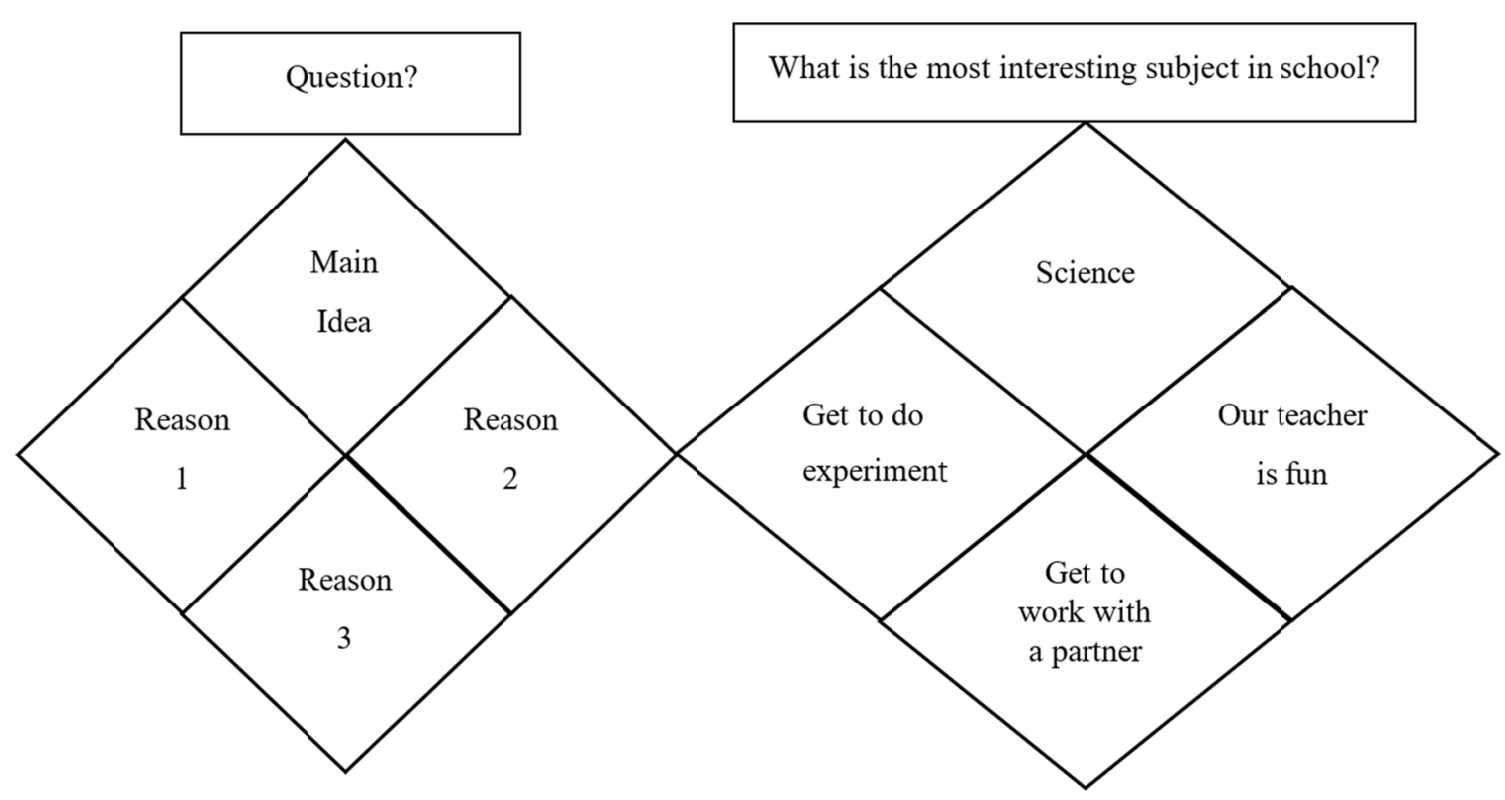

Figure 1. Diamond graphic organizer

Lesson 3: Supported practice. After memorization practice, the student and instructor collaboratively wrote a persuasive essay using all the steps in POWER UP. The student was given a blank piece of paper, and blank "idea diamond" graphic organizer, POWER UP checklist, and a practice prompt. The instructor prompted the student to use all parts of the POWER UP strategy. The teacher collaboratively developed reasons and supporting explanations. Students were encouraged to check off each step of POWER UP as they completed it using the POWER UP checklist. After writing and revising the essay following the POWER UP steps, students counted the number of words they wrote and looked for important essay elements (e.g., main idea, supporting statements, ending sentence).

Lesson 4: Guided practice writing a 30-minute timed persuasive response. During lesson 4, the instructor guided the students individually as they independently used the POWER UP strategy with the teacher giving explicit instruction and corrections, as necessary. The purpose of this lesson was to check for student mastery of the steps to use POWER UP. If a student struggled or needed more than a simple prompt, the instructor was prepared to provide additional instruction to ensure the student had mastered the steps.

Data were not collected during the POWER UP instruction phase as participant performance was supported by the instructor and did not accurately reflect independent use of the strategy. Participants remained in the instruction phase until reaching the criterion for independent performance. The criterion for independent performance was met when participants could correctly use each step of the POWER UP strategy without support from the instructor. Once the first participant met the criterion, the participant moved into the post-instruction phase and began completing the prompts independently once a week using the POWER UP strategy. These probes were administered under the same conditions as the baseline probes. Once a participant had completed the instruction phase, the next participant was taught the POWER UP strategy. The criterion was met for all participants in 4 lessons.

\subsection{Treatment Fidelity}

The following procedures were used to ensure consistent implementation of the POWER UP strategy. First, the instructor communicated daily with the first author to discuss the day's lesson and discuss plans for the next lesson. Second, during instruction the instructor used a fidelity checklist created for each lesson. The instructor was required to check each completed step on the checklist as it occurred before moving on to the next step of the lesson. Treatment fidelity for the instructor was $100 \%$.

\section{Results}

Data were analyzed via visual inspection to examine stability, level, and trend (Kazdin, 1982). There was an overall improvement in the persuasive writing of all participants following SRSD instruction of POWER UP. Figures 2 and 3 display the results for quality of responses and number of words written. Effect size estimates 
were calculated using Nonoverlap of All Pairs (NAP), following guidelines by Parker, Vannest and Brown, 2009. Parker, Vannest, and Brown (2009) recommended the following NAP interpretation guidelines: weak effects: 0-.65, moderate effects: .66-.92, and large or strong effects: .93-1.0.

Upon visual inspection of the data, each of the participants improved their persuasive writing performance when they were taught the POWER UP strategy as measured by the NeSA analytic 4-trait rubric for persuasive writing. During baseline Christian had a stable performance with an average quality score of 221.6 (SD 23.6). After being taught the POWER UP strategy, his performance immediately improved and remained consistent thereafter with an average score of 317.7 (SD 32.4). The effect size calculation for NAP was 1.0, which would suggest a strong effect for use of the strategy. KaVionne had a stable baseline except for one data point that scored a little higher (155). His average baseline score was 90.8 (SD 33.3). After learning the strategy, KaVionne's performance immediately improved and remained somewhat stable except for one data point (160) that dropped towards baseline. His average score after learning the strategy was 249.1 (SD 56.0) with an effect size calculation of 1. Tyler's baseline was somewhat variable with a downward trend. His average baseline score was 120.5 (SD 54.1). After learning the strategy, Tyler's scores improved and remained stable with an average score of 286.6 (SD 23.0) and an effect size calculation of 1.0.

Baselin Intervention Independent Performance

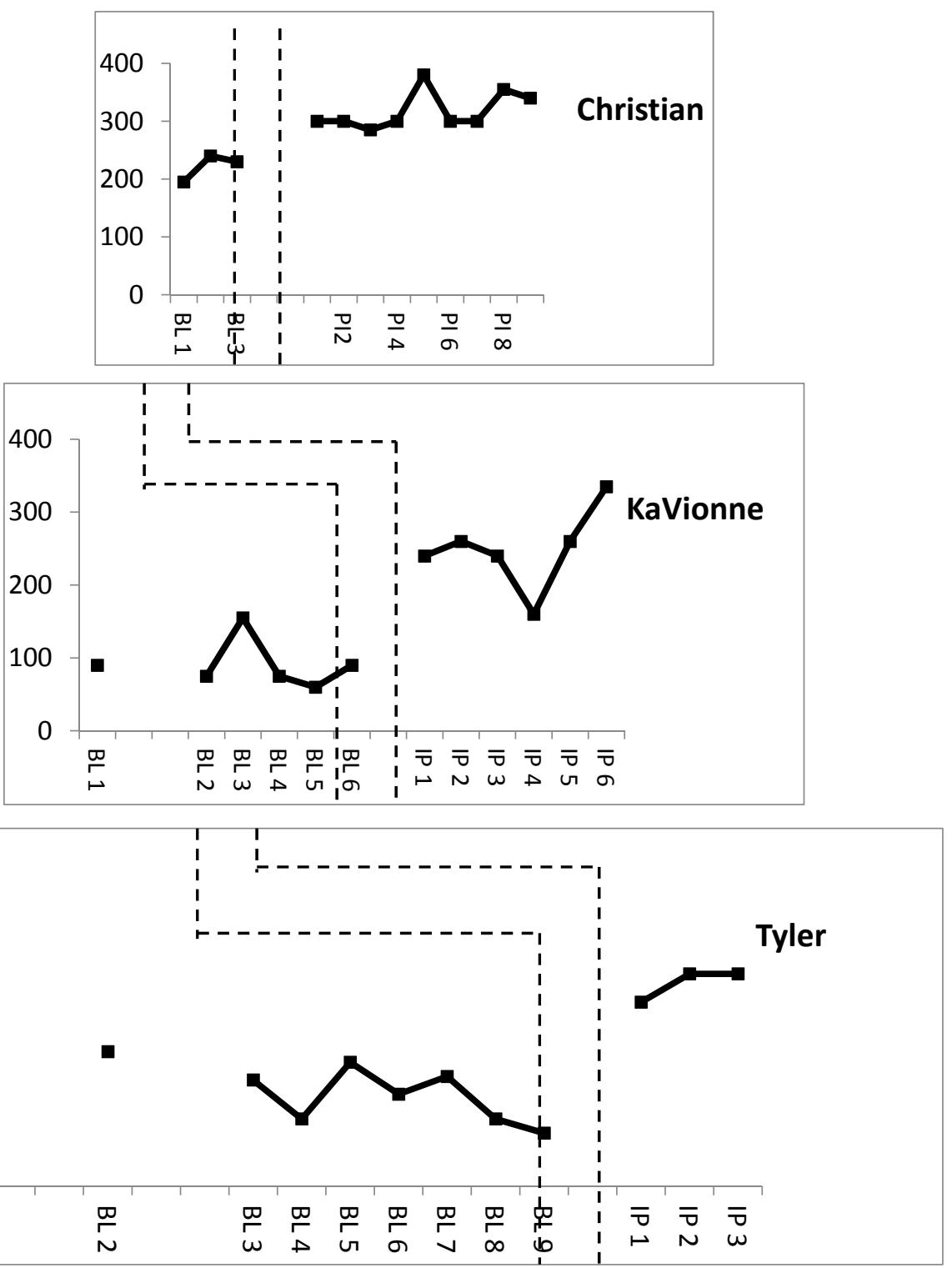

Figure 2. Student performance as assessed by the NeSA Rubric for persuasive writing 
Visual inspection of the data from the number of words written showed more variability than the analytic data. During baseline Christian's number of words written was showing a downward trend with an average count of 178.6 (SD 31.5).

Baselin Intervention Independent Performance
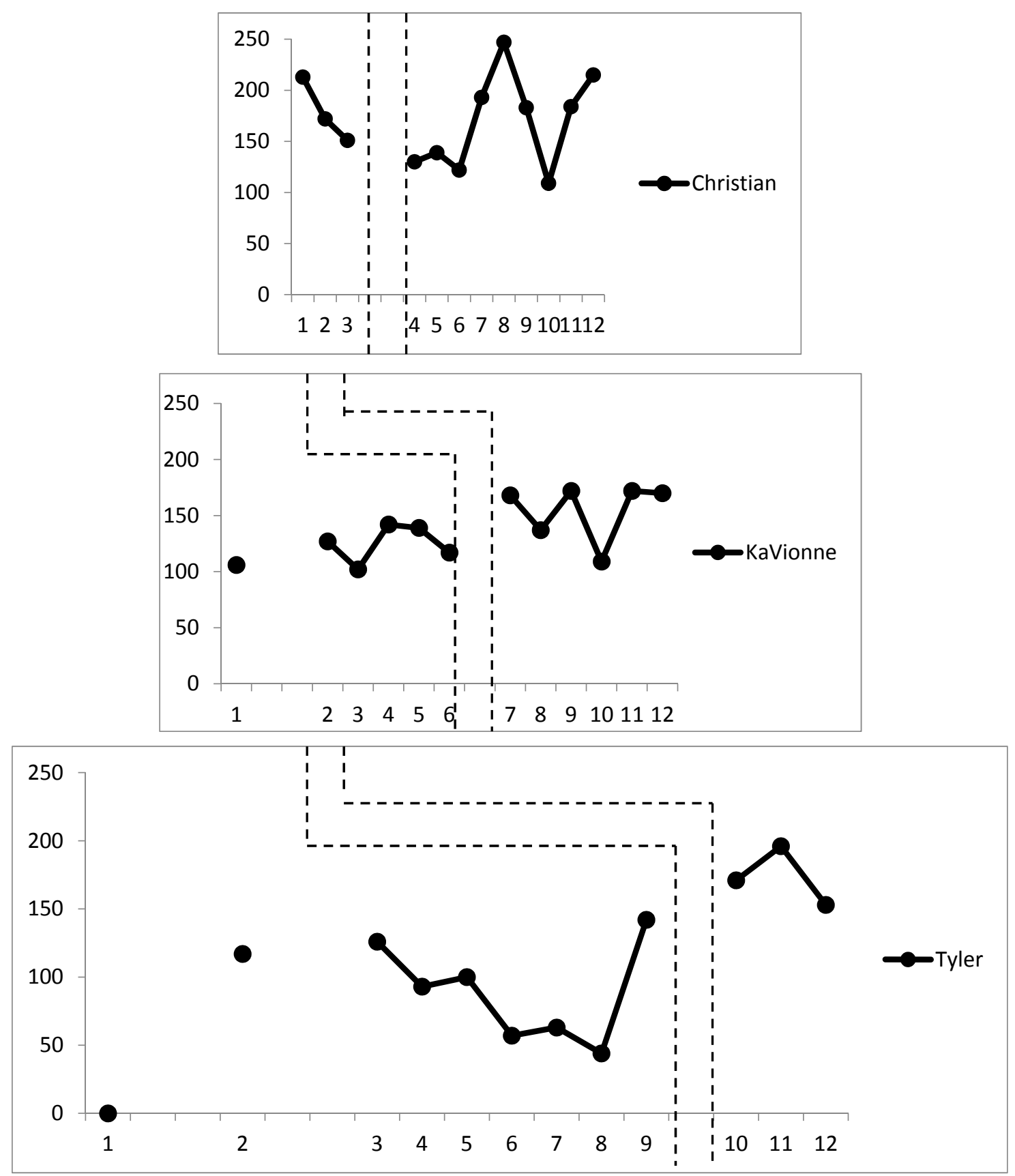

Figure 3. Number of words written

Upon learning the POWER UP strategy, Christian's number of words continued to show great variability with an average score of 169.1 (SD 46.6). The effect size calculation for NAP was .44, which would suggest a weak effect on the number of words written. KaVionne had a stable baseline with little variability and an average number of words written of 122.1 (SD 16.7). His words written after learning the strategy showed a slight increase with an average of 154.6 (SD 26.1). The effect size calculation for NAP was .83, which would suggest a moderate effect on the number of words written. Tyler's number of words written during baseline showed a 
downward trend with some variability until the last baseline data point which was very high. His average number of words written was 82.4 (SD 45.2). After learning the strategy, Tyler's number of word written continued to show some variability with an average word count of 173.3 (SD 21.5) and a calculated effect size of 1.0, which would suggest a strong effect of the strategy on word count.

\section{Discussion}

The results of this study suggest that the POWER UP strategy paired with strategy instruction using the SRSD model can improve the quality of persuasive writing of high school students with EBD. Upon visual inspection all of the students' essay quality improved immediately following strategy instruction. In addition, the NAP data for all participants was 1.0, which further indicates a strong effect of the strategy on the quality of the students' persuasive writing. The results from this study are consistent with previous research that suggests writing strategies can improve the quality of written work for struggling writers. Thus, the findings from this study provide additional evidence that strategies such as POWER UP, when taught using a strategy instruction model such as SRSD, can help students improve their quality of writing in a relatively short amount of time.

\subsection{POWER UP Strategy}

This study investigated the effects of the modified POWER strategy. Students were taught the POWER UP strategy to improve their persuasive writing performance for the statewide examination. Results suggest that the quality of essays written improved after students were taught the POWER UP strategy. The effects of strategy instruction on essay length were not as pronounced as the effects found in quality. There are two possible explanations for this. First, the data for this measure were more variable than for quality (i.e., analytic), which affected the effect size. Second, this study was conducted within the daily classroom routine and schedule. Therefore, there was a time limit for how long the students were allowed to write. As a result, students may not feel they have enough time to write longer explanations to support their persuasive arguments. However, despite this, it is important to note that all students showed increases or maintained a consistent number of words written. For the state examination, the students will have unlimited time to complete their essays which may result in a higher word count.

\subsection{Classroom Teacher Implementing POWER UP}

This study adds to the limited research base investigating the effects of classroom teachers implementing SRSD. Until recently, the majority of research on SRSD was implemented by researchers or trained doctoral students in somewhat controlled settings. In this study, a classroom teacher in a self-contained setting implemented the POWER UP strategy to three high school students with EBD on her caseload. The results were consistent with previous studies involving SRSD and writing strategies. For example, the teacher was able to implement strategy instruction with $100 \%$ fidelity, indicating that all elements of SRSD were included in instruction. Moreover, the teacher was able to implement the interventions as part of the typical classroom routine. This would suggest that classroom teachers can implement SRSD in a reasonable amount of time and can deliver strategy instruction effectively in their own classrooms.

\subsection{Students with EBD}

Students with EBD tend to have some of the lowest scores in the area of written language on standardized tests. As a result, they experience high rates of school failure and are less likely to pass statewide examinations. Unfortunately, there is a lack of research on writing interventions for students with EBD, so it is likely these low scores will continue until researchers conduct larger scale studies and include teachers in the intervention process. In this study, conducted in collaboration with a classroom teacher, each of the participants showed a marked improvement in the quality of their writing as measured by the statewide assessment rubric. Given the limited research on writing interventions for students with EBD and lack of research with classroom teachers implementing the intervention, the findings from this study can provide a starting point for conducting large scales studies that may allow for a broader generalization of these results and improve outcomes for students with EBD.

\subsection{Limitations and Future Research}

There are several limitations to the present study. First, because a treatment package consisting of the POWER UP strategy along with graphic organizers, self-regulation interventions and goal setting was used, we cannot determine which component was responsible for the observed effects. Future research should attempt to determine if the POWER UP strategy, use of graphic organizers to plan instruction, goal setting and self-monitoring, or a combination of the three is responsible for the effects found in this study. Second, we did not assess generalization to other settings, thus we are unaware if the students applied the strategy to improve 
their performance in other settings. Third, we conducted this study during the Spring semester, which meant that we had a limited amount of time to conduct the study before school let out for the summer. As a result, we were only able to conduct three probes after the intervention for Tyler and we were unable to do any follow-up probes on the effect of the strategy for any of the participants. Additional research should be conducted to determine if students continue to use the strategy and to determine its effect on their writing performance over time. Fourth, as with any single-subject research design, our sample size was small. Replication of the intervention used in this study should be conducted with a larger, and more diverse sample to support its conclusions and to investigate its use with other populations. Fifth, because this study was conducted during a typical school day, the teacher in this study had to implement the intervention during a half hour class period. This may have impacted the results of this study as teachers had limited time for instruction and students' planning and writing were limited within the thirty-minute class period. Academic settings that provide longer class periods may find improved outcomes with additional time for instruction and student writing. Finally, this study only looked at the use of the SRSD model for persuasive writing skills for students with EBD. Future research should investigate the application of SRSD within other academic content areas for students with EBD.

\subsection{Implications}

Given the lack of research on academic writing interventions for students with EBD the results from this research should not be ignored. The results of this study suggest that that the POWER UP strategy taught using the SRSD model can be effective in improving the writing quality of high school students with EBD. In a relatively short period of time, participant written quality increased as measured by a state writing rubric. Given the increasing emphasis on statewide assessments and the continuing involvement of students with disabilities in these assessments, the importance of identifying strategies to help them be successful is critical to improving outcomes for students with EBD. There is a desperate need for continued research on academic interventions for students with EBD. Previous research on strategic instruction for students with learning disabilities has been encouraging and positive. As demonstrated in this study, the application of those strategies to students with EBD holds great promise and might set the stage for improving academic outcomes for students with EBD.

\section{References}

Benner, G. J., Mattison, R. E., Nelson, J. R., \& Ralston, N. C. (2009). Types of language disorders in students classified as ED: Prevalence and association with learning disabilities and psychopathology. Education \& Treatment of Children, 32, 631-653. https://doi.org/10.1353/etc.0.0077

Englert, C. S., Raphael, T. E., Anderson, L. M., Anthony, H. M., Fear, K. L., \& Gregg, S. L. (1988). A case for writing intervention: Strategies for writing informational text. Learning Disabilities Focus, 3, 98-113.

Englert, C. S., Raphael, T. E., Anderson, L. M., Anthony, H. M., \& Stevens, D. D. (1991). Making Strategies and Self-Talk Visible: Writing Instruction in Regular and Special Education Classrooms. American Educational Research Journal, 28, 337-372. https://doi.org/10.3102/00028312028002337

Graham, S. (2005). Writing interventions and strategies. In S. Lee (Ed.), Encyclopedia of school psychology (pp. 587-590). Thousand Oaks, CA: Stage. https://doi.org/10.4135/9781412952491.n311

Graham, S., Harris, H. R, MacArthur, C., \& Schwartz, S. (1991). Writing and writing instruction with students with learning disabilities: A review of a program of research. Learning Disability Quarterly, 14, 89-114. https://doi.org/10.2307/1510517

Harris, K. R., Graham, S., \& Mason, L. H. (2006). Improving the writing, knowledge, and motivation of struggling young writers: Effects of self-regulated strategy development with and without peer support. American Educational Research Journal, 43, 295-340. https://doi.org/10.3102/00028312043002295

Kazdin, A. E. (1982). Single-case research designs: Methods for clinical and applied settings. New York: Oxford University Press.

Lane, K. L. (2004). Academic instruction and tutoring interventions for students with emotional/behavioral disorders: 1990 to present. In R. B. Rutherford, M. M. Quinn \& S. R. Mathur (Eds.), Handbook of research in emotional and behavioral disorders (pp. 462-486). New York: Guilford Press.

Lane, K. L., Harris, K, Graham, S., Weisenbach, J., Brindle, M., \& Morphy, P. (2008). The effects of self-regulated strategy development on the writing performance of second grade students with behavioral and writing difficulties. Journal of Special Education, 41, 234-253. https://doi.org/10.1177/0022466907310370

Little, M. A., Lane, K. L., Harris, K. R., Graham, S., Story, M., \& Sandmel, K. (2010). Self-regulated strategies 
development for persuasive writing in tandem with schoolwide positive behavioral support: Effects for second-grade students with behavioral and writing difficulties. Behavioral Disorders, 35, 157-179.

Mason, L. H., Kubina, R. M., \& Hoover, T. (2013). Effects of quick writing instruction for high school students with emotional disturbances. Journal of Emotional and Behavioral Disorders, 21, 163-175. https://doi.org/10.1177/1063426611410429

Mason, L. H., Kubina Jr., R. M., Valasa, L. L., \& Cramer, A. M. (2010). Evaluating effective writing instruction for adolescent students in an emotional and behavior support setting. Behavioral Disorders, 35, 140-156.

Mason, L. H., \& Shriner, J. G. (2008). Self-regulated strategy development instruction for writing an opinion essay: Effects for six students with emotional/behavior disorders. Reading \& Writing, 21, 71-93. https://doi.org/10.1007/s11145-007-9065-y

Mooney, P., Epstein, M. H., Reid, R., \& Nelson, J. (2003). Status of and trends in academic intervention research for students with emotional disturbance. Remedial \& Special Education, 24, 273-287. https://doi.org/10.1177/07419325030240050301

Nebraska Department of Education. (2012). Retrieved from http://www.education.ne.gov/assessment/NeSA_Writing.htm

Nelson, J. R., Benner, G. J., Lane, K., \& Smith, B. W. (2004). An investigation of the academic achievement of K-12 students with emotional and behavioral disorders in public school settings. Exceptional Children, 71, 59-73. https://doi.org/10.1177/001440290407100104

Parker, R. I., Vannest, K. J., \& Brown, L. (2009). The improvement rate difference for single-case research. Exceptional Children, 75, 135-150. https://doi.org/10.1177/001440290907500201

Reid, R., Gonzalez, J. E., Nordness, P. D., Trout, A., \& Epstein, M. H. (2004). A meta-analysis of the academic status of students with emotional/behavioral disturbance. Journal of Special Education, 38, 130-143. https://doi.org/10.1177/00224669040380030101

Reid, R., Trout, A. L., \& Schwartz, M. (2005). Self-regulation interventions for children with attention deficit/hyperactivity disorder. Exceptional Children, 71, 361-377.

Taft, R., \& Mason, L. H. (2011). Examining effect of writing interventions: Spotlighting results for students with primary disabilities other than learning disabilities. Remedial and Special Education, 32, 359-370. https://doi.org/10.1177/0741932510362242

Trout, A., Nordness, P. D., Pierce, C. D., \& Epstein, M. H. (2003). Research on the academic status of children and youth with emotional and behavioral disorders: A review of the literature from 1961-2000. Journal of Emotional and Behavioral Disorders, 11, 198-210. https://doi.org/10.1177/10634266030110040201

\section{Copyrights}

Copyright for this article is retained by the author, with first publication rights granted to the journal.

This is an open-access article distributed under the terms and conditions of the Creative Commons Attribution license (http://creativecommons.org/licenses/by/4.0/). 